\title{
Estimation of Permeability from NMR Logs Based on Formation Classification Method in Tight Gas Sands
}

\author{
Deng-Feng $\mathrm{WEI}^{1}$, Xiao-Peng $\mathrm{LIU}^{2}$, Xiao-Xin $\mathrm{HU}^{2}$, Rui XU ${ }^{3}$, \\ and Ling-Ling $\mathrm{ZHU}^{3}$
}

\begin{abstract}
${ }^{1}$ School of Graduate Student, College of Resources and Environment, Southwest Petroleum University, Sichuan, PR China; e-mail: 13101103@qq.com

${ }^{2}$ Geological Exploration and Development Research Institute, Sichuan-Changqing Drilling and Exploration Engineering Corporation, CNPC, Sichuan, PR China

${ }^{3}$ Tuha Division of CNPC Well Logging Company Ltd., Xinjiang, PR China
\end{abstract}

\section{Abstract}

The Schlumberger Doll Research (SDR) model and cross plot of porosity versus permeability cannot be directly used in tight gas sands. In this study, the HFU approach is introduced to classify rocks, and determine the involved parameters in the SDR model. Based on the difference of FZI, 87 core samples, drilled from tight gas sandstones reservoirs of E basin in northwest China and applied for laboratory NMR measurements, were classified into three types, and the involved parameters in the SDR model are calibrated separately. Meanwhile, relationships of porosity versus permeability are also established. The statistical model is used to calculate consecutive FZI from conventional logs. Field examples illustrate that the calibrated SDR models are applicable in permeability estimation; models established from routine core analyzed results are effective in reservoirs with permeability lower than $0.3 \mathrm{mD}$, while the unified SDR model is only valid in reservoirs with permeability ranges from 0.1 to $0.3 \mathrm{mD}$.

Key words: tight gas sandstones, permeability, formation classification method, SDR model, nuclear magnetic resonance (NMR) logs. 


\section{INTRODUCTION}

Permeability calculation is of great importance in formation evaluation and deliverability prediction (Mao et al. 2013). There is no conventional log to be used to directly calculate permeability. Generally, permeability prediction is always relied on a good relationship of core derived porosity and permeability in conventional reservoirs (Salah 2012, Deng et al. 2013, Delli and Grozic 2013, Hulea 2013). However, the permeability estimation faces a great challenge in tight gas sands and carbonate formations (Hulea and Nicholls 2012, Xiao et al. 2014). The relationship between core derived porosity and permeability cannot be expressed by a single function due to the complicated pore types, structure, and high degree of heterogeneity (Lucia 1995, Xiao and Xiao 2008). In the right panel of Fig. 1, we show a cross plot of core derived porosity and permeability; the core samples were drilled from tight gas sandstone reservoirs in five adjacent wells of $\mathrm{E}$ basin in northwest China. The left panel of Fig. 1 displays the micro-resistivity scanning imaging log response obtained from STAR II tool; this figure is acquired from the same interval with the plug samples marked using ellipse in the right panel of this figure. In the E basin, all core derived porosities are measured by using the helium gas injection method, and to acquire fluid permeability for routine core analysis in tight gas sandstones, an instantaneous-pulse permeability test method instead of the conventional steady-state method was applied. By using the instantaneous-pulse permeability test method, the extremely low permeability of $0.000001 \mathrm{mD}$ can also be measured under the experimental conditions of confinement pressure of 10.0 $60.0 \mathrm{MPa}$, and pore pressure of $0.0 \sim 15.0 \mathrm{MPa}$ (Yang 2001). In the process of experimental measurement, we simulated the formation conditions. Hence, the measured results are reservoir fluid permeabilities, and no additional corrections (such as stress correction) needed to be made (Gao et al. 1991). From Fig. 1, it can be observed that in tight gas sands of $\mathrm{E}$ basin, the related function cannot be established to directly calculate permeability from porosity. If the relationship is constrainedly established, inaccurate permeability is obtained. Meanwhile, micro-resistivity scanning imaging log data illustrated that in the target formations of $\mathrm{E}$ basin, the intergranular pore is dominant, and only few fractures developed in formations with extreme matrix porosity (the marked area in Fig. 1), which had been verified by Mao et al. (2008). Hence, in our target tight gas sands, formations are dominant by matrix permeability. Rezaee et al. (2012) and Xiao et al. (2014) pointed out that permeability estimation model can be established from mercury injection capillary pressure (MICP) data in tight gas sands, and Hulea and Nicholls (2012) estimated permeability from the total normalized pore-throat radius in heterogeneous carbonate rocks. However, all these models were established 


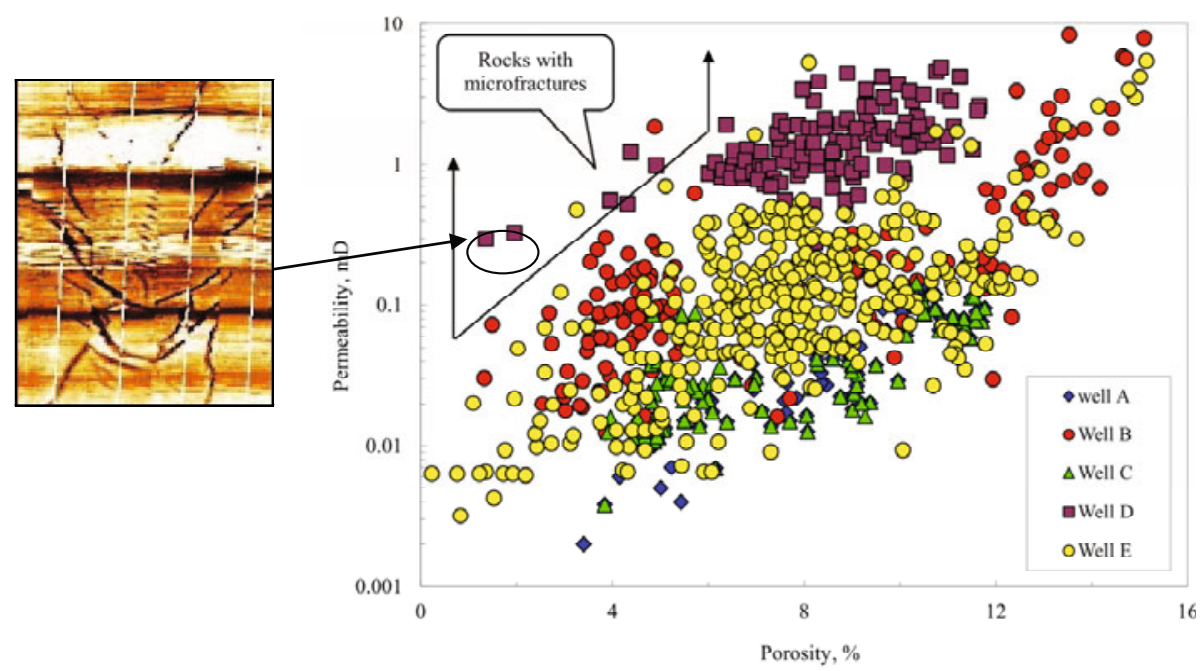

Fig. 1. The cross plot of core derived porosity and permeability for core samples drilled from five adjacent wells in tight gas sands of $\mathrm{E}$ basin in northwest China.

based on the laboratory experimental measurements, no cases had been exhibited to introduce how these can be used in field applications, and those intermediate parameters were hardly acquired from conventional or nuclear magnetic resonance (NMR) logs at present. Coates et al. (1999) and Dunn et al. (2002) pointed out that NMR logs can be used to estimate permeability. In this paper, we will analyze the applicability of NMR logs in tight gas sandstone permeability estimation, and propose appropriate method to calculate permeability from NMR logs.

\section{PERMEABILITY ESTIMATION FROM NUCLEAR MAGNETIC RESONANCE (NMR) LOGS}

\subsection{Classical permeability prediction models based on NMR logs}

Nuclear magnetic resonance (NMR) logs are effective in predicting permeability (Coates et al. 1999, Dunn et al. 2002). From NMR logs, two proposed models can be used to calculate permeability; they are known as the SDR and Timur-Coates models (Kenyon 1997, Kenyon et al. 1988, Coates et al. 1999). The SDR and Timur-Coates models are expressed as follows:

$$
\begin{gathered}
K=C_{1} \times \phi^{m_{1}} \times T_{2 \mathrm{~lm}}^{n_{1}}, \\
K=\left(\frac{\phi}{C_{2}}\right)^{m_{2}} \times\left(\frac{\mathrm{FFI}}{\mathrm{BVI}}\right)^{n_{2}},
\end{gathered}
$$


where $K$ is the permeability (in $\mathrm{mD}$ ); $\varphi$ is the total porosity (in $\%$ ); $T_{21 \mathrm{~m}}$ is the logarithmic mean of NMR $T_{2}$ spectra (in ms); FFI is the free fluid bulk (in $\%$ ); BVI is the bulk volume irreducible (in \%); $m_{1}, n_{1}, C_{1}, m_{2}, n_{2}$, and $C_{2}$ are the statistical model parameters, whose values can be derived from lab NMR experimental data sets of core samples. When not enough core samples are usable, $m_{1}, n_{1}, C_{1}, m_{2}, n_{2}$, and $C_{2}$ are assigned to empirical values of 4, 2, 10, 4, 2, and 10, respectively (Mao et al. 2013).

\subsection{Limitations of permeability estimation model in tight sandstone res- ervoirs}

From Eqs. 1 and 2, it can be observed that permeability can be estimated from NMR logs once the values of $m_{1}, n_{1}, C_{1}, m_{2}, n_{2}$, and $C_{2}$ are first calibrated and the necessary input parameters of $\varphi, T_{21 \mathrm{~m}}, \mathrm{FFI}$, and BVI can be precisely obtained. $\varphi$ and $T_{2 \mathrm{~m}}$ can be acquired from NMR logs after the necessary hydrocarbon correction has been made (Xiao et al. 2012a, b, c). The values of FFI and BVI can be calculated from NMR logs as follows (Morriss et al. 1997):

$$
\begin{gathered}
\mathrm{BVI}=\frac{\int_{T_{\min }}^{T_{2 \text { cutfif }}} S(T) d t}{\int_{T_{2 \min }}^{T_{\max }} S(T) d t} \times 100 \%, \\
\mathrm{FFI}=100-\mathrm{BVI},
\end{gathered}
$$

where $T_{2 \min }$ is the minimum horizontal relaxation time, $T_{2 \max }$ is the maximum horizontal relaxation time, $T_{2 \text { cutoff }}$ is the $T_{2}$ cutoff, and the units of them are microsecond. $S(T)$ is the porosity distribution function, which is associated with the $T_{2}$ relaxation time.

Equations 3 and 4 illustrate that if one wants to calculate FFI and BVI from NMR logs, $T_{2 \text { cutoff }}$ must be first determined. The histogram method is always used to determine a fixed $T_{2 \text { cutoff }}$ for calculating FFI and BVI from NMR logs (Xiao et al. 2012a, b, c; Mao et al. 2013). Field applications illustrate that defining fixed $T_{2 \text { cutoff }}$ to calculate FFI and BVI is not always effective. Figure 2 shows the statistical histogram of $T_{2 \text { cutoff }}$ of 87 core samples, which were drilled from the same tight gas reservoirs as Fig. 1, and the $T_{2 \text { cutoff }}$ were obtained by using the centrifugal displacement method. The principle of obtaining $T_{2 \text { cutoff }}$ with centrifugal displacement method is illustrated in Fig. 3.

From the statistical $T_{2 \text { cutoff }}$ shown in Fig. 2 we can observe that in tight gas sands, not a fixed $T_{2 \text { cutoff }}$ can be acquired to calculate FFI and BVI from NMR measurements in the whole intervals. To calculate accurate FFI and BVI, the optimal method is obtaining variable $T_{2 \text { cutoff }}$ with the depth. How- 


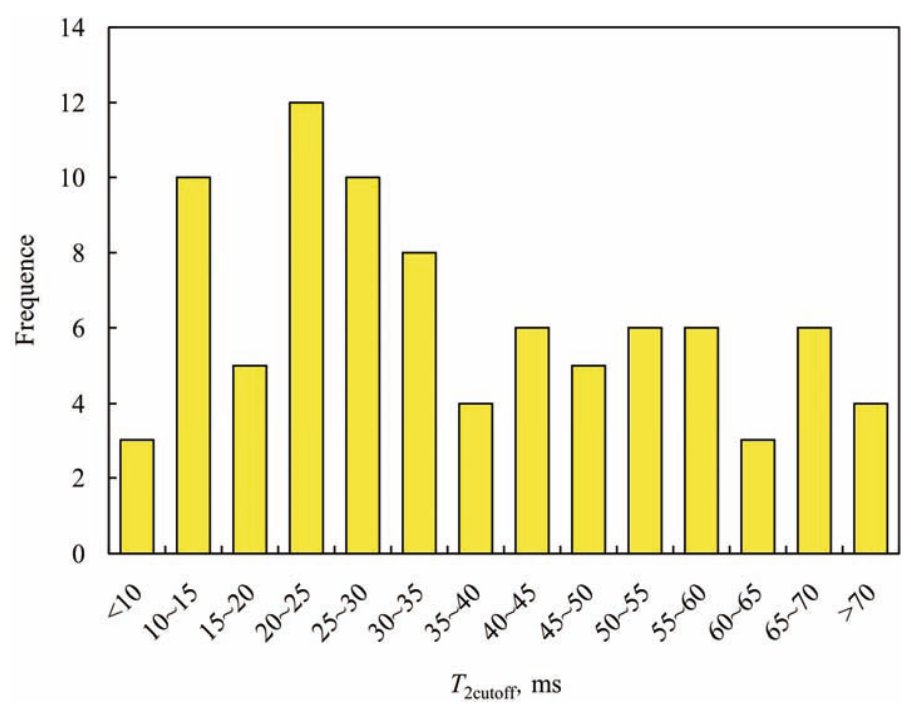

Fig. 2. The statistical histogram of $T_{\text {2cutoff }}$ for 87 core samples drilled from tight sandstone reservoirs of $\mathrm{E}$ basin in northwest China.

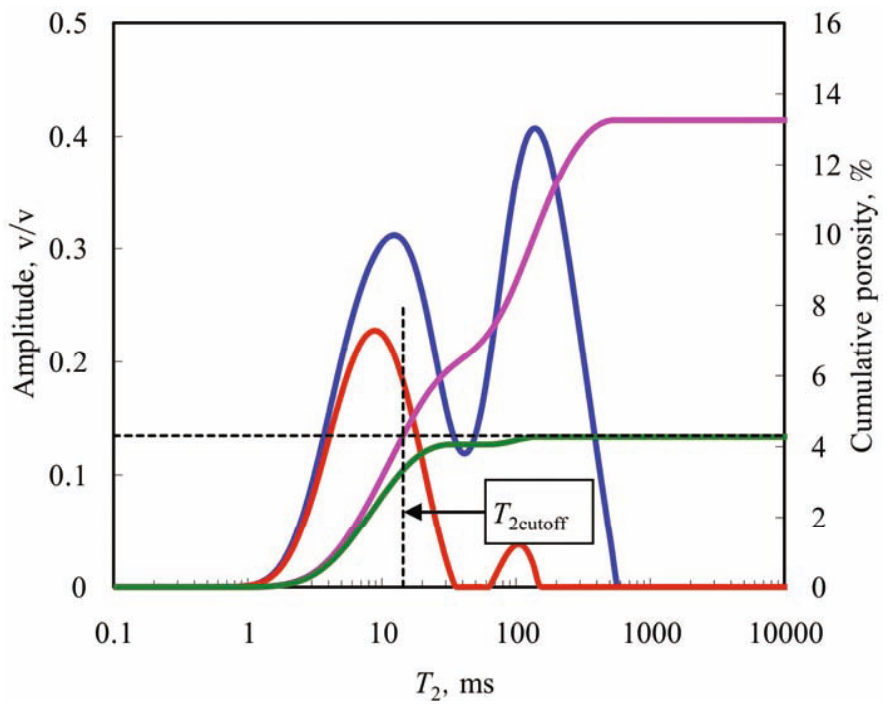

Fig. 3. The principle of obtaining $T_{2 \text { cutoff }}$ from NMR measurement with centrifugal displacement method.

ever, there is no effective method to obtain variable $T_{2 \text { cutoff }}$ at present (Xiao et al. 2012a, b, c). This makes a great challenge of calculating permeability by using the Timur-Coates model. Therefore, the SDR model is very popular in permeability estimation in practical applications (Mao et al. 2013). 
To calculate permeability from NMR logs by using the SDR model, the parameters $C_{1}, m_{1}$, and $n_{1}$ needed to be first calibrated. In this study, 87 core samples drilled from tight gas sands in the $\mathrm{E}$ basin of northwest China were chosen for laboratory NMR measurements. By using the NMR experimental results, the SDR model was calibrated and expressed as follows:

$$
K=0.00000389 \times \phi^{2.302} \times T_{2 \mathrm{~lm}}^{1.373}, \quad R^{2}=0.682 .
$$

Figure 4 displays the relationship of core derived porosity and permeability for the same 87 core samples. If we only observe the correlation coefficients listed in Fig. 4 and Eq. 5, we may conclude that permeability can be directly estimated from NMR logs by using the unified SDR model. However, if we observe Fig. 4 in detail, we can find out that the relationship is much worse; although good correlation coefficient exist between them, most of the core samples cannot pass by the regressed trend line, and they are scattered on both sides of the trend line. This means that permeability may be overestimated or underestimated from NMR logs by using the unified calibrated SDR model. To improve the applicability of SDR model in tight gas sands, formation classification method is introduced to classify reservoirs into several types, and the above-mentioned parameters in the SDR model are calibrated in every type of reservoir separately.

The hydraulic flow unit (HFU) approach is used in formation classification. In the next section, we will introduce tight gas sandstone permeability estimation method based on formation classification.

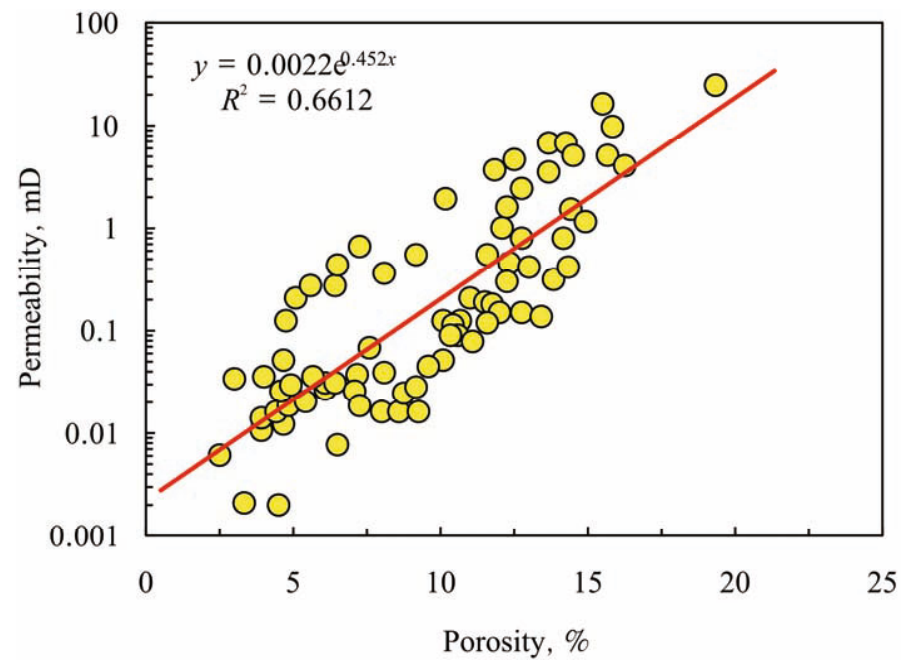

Fig. 4. The cross plot of core derived porosity and permeability for core samples with laboratory NMR measurements. 


\section{PERMEABILITY PREDICTION FROM NMR LOGS BASED ON FORMATION CLASSIFICATION METHOD}

\subsection{The hydraulic flow unit (HFU) approach}

A HFU is a reservoir zone that is continuous laterally and vertically with similar permeability, porosity, and bedding characteristics (Hearn et al. 1984). Rocks with similar permeability, porosity, and bedding characteristics often have similar pore throat attributes and therefore belong to the same HFU. The HFU is often used to classify formation, and it is of great help for the evaluation of reservoir classification with strong heterogeneity (D'Windt 2007).

Based on a modified Kozeny-Carman equation and the concept of mean hydraulic radius, Tiab et al. (1993) developed a generalized formula of the relationship between porosity and permeability; this formula can be expressed as follows:

$$
K=\frac{\phi^{3}}{(1-\phi)^{2}} \times \frac{1}{K_{T} S_{V_{\mathrm{gr}}}^{2}},
$$

where

$$
K_{T}=K_{\mathrm{ps}} \tau,
$$

and $S_{V \mathrm{gr}}$ is the specific surface area per unit grain volume in $\mathrm{m}^{2} / \mathrm{cm}^{3}, K_{\mathrm{ps}}$ is the pore shape factor, $\tau$ is the pore tortuosity, and $K_{T}$ is the pore-level effective zoning factor. Though varying among flow units, this parameter is constant within a given unit.

If the unit of permeability is transformed from $\mu \mathrm{m}^{2}$ to millidarcy, the following formula can be obtained by dividing both sides of Eq. 6 by porosity and taking the square root of both:

$$
0.0314 \times \sqrt{\frac{K}{\phi}}=\frac{\phi}{1-\phi} \times \frac{1}{\sqrt{K_{T}} S_{V_{\mathrm{gr}}}},
$$

where 0.0314 is the conversion coefficient for $K$ from $\mu \mathrm{m}^{2}$ to $\mathrm{mD}$.

There are three important parameters in the HFU theory and they are defined as follows:

(1) Reservoir quality index (RQI): RQI is defined as follows:

$$
\mathrm{RQI}=0.0314 \times \sqrt{\frac{K}{\phi}} ;
$$

(2) Flow zone indicator (FZI): FZI is defined as:

$$
\mathrm{FZI}=\frac{1}{\sqrt{K_{T}} S_{V_{\mathrm{gr}}}} ;
$$


(3) Normalized porosity $\left(\varphi_{z}\right)$ : Normalized porosity is defined as:

$$
\phi_{z}=\frac{\phi}{1-\phi} .
$$

By carrying out some algebraic transformations for Eq. 8, the expression of FZI can be rewritten as follows:

$$
\mathrm{FZI}=0.0314 \times \sqrt{\frac{K}{\phi}} \times \frac{1-\phi}{\phi} .
$$

\subsection{Determination of formation classification criteria}

Based on the analysis above section, the boundary of the FZI needed to be first determined to classify formations. If we substitute Eqs. 9 to 11 into 8 and take logarithms on both sides, Eq. 8 can be transformed as follows:

$$
\log (\mathrm{RQI})=\log (\mathrm{FZI})+\log \left(\phi_{z}\right) .
$$

Equation 13 illustrates that for core samples with the same FZI, the relationship of $\varphi_{z}$ versus RQI in log-log coordinates will be a straight line, and core samples with a different FZI will be on other parallel lines.

To obtain the classification criteria of FZI to classify formation, 87 core samples displayed in Fig. 4 are processed by using of the theory of HFU. The cumulative frequency distribution of FZI and the cross plot of $\varphi_{z}$ versus RQI for 87 core samples are displayed in Figs. 5 and 6, separately. From

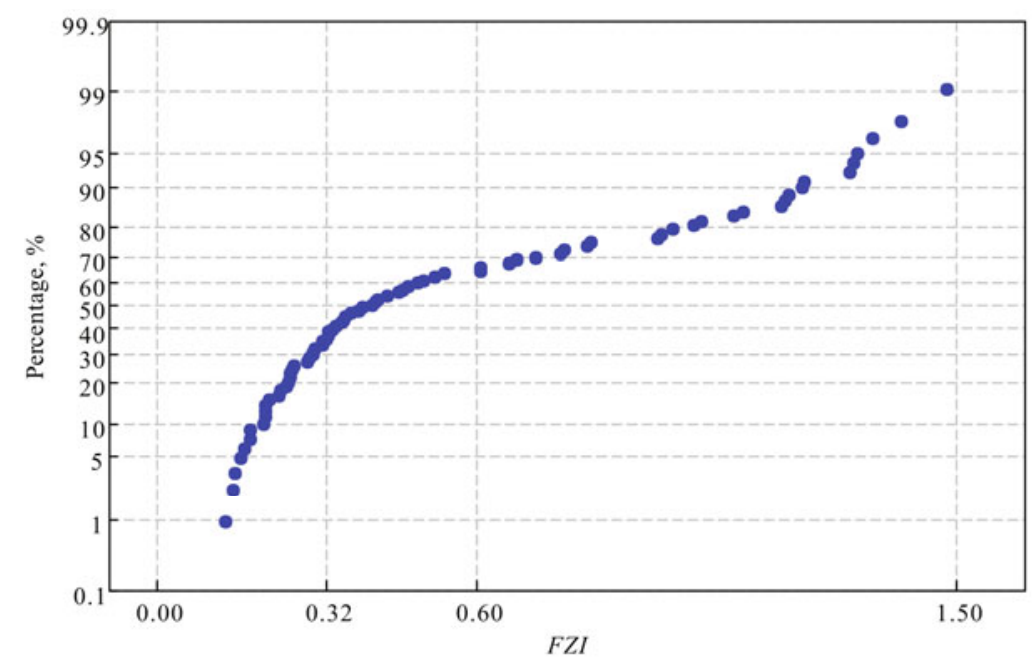

Fig. 5. The cumulative frequency distribution of FZI for 87 core samples in our target tight gas sandstone reservoirs. 


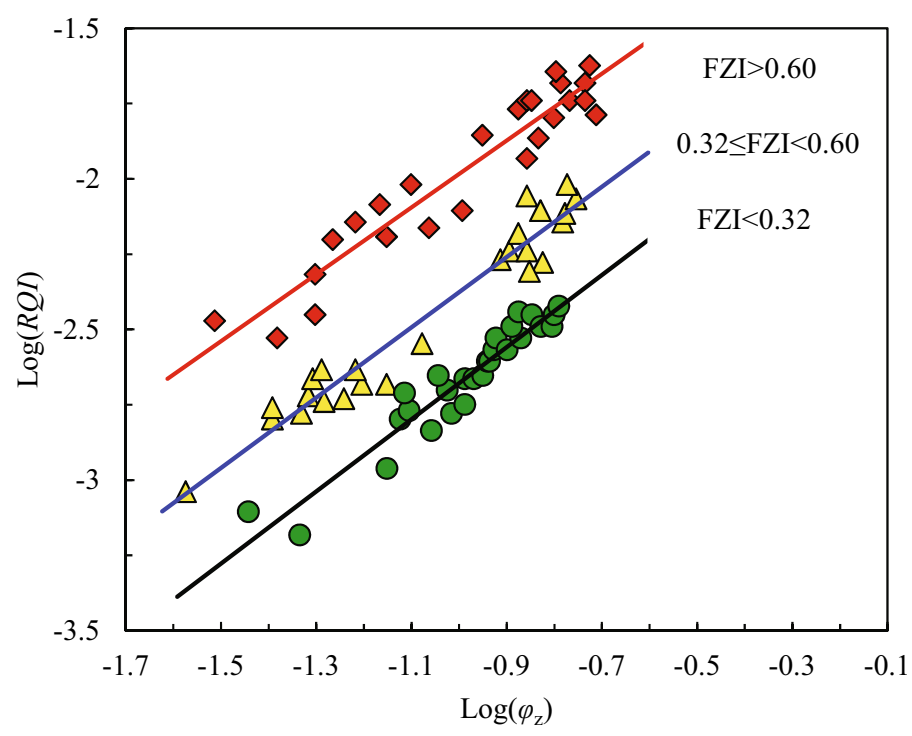

Fig. 6. The cross plot of $\varphi_{z}$ versus RQI in log-log coordinates for the target core samples.

these two figures, we can conclude that in our target tight gas sandstone reservoirs, the best classification of HFU is for three types; the boundary values of FZI for different types of formations are 0.32 and 0.60 . Maybe, the permeability estimation can be a little improved; after formations are classified into many more types, a larger workload will be introduced.

To verify the reasonableness of formation classification based on the difference of FZI, 3 representative core samples, which contain similar porosity but belong to different FZI, were chosen for MICP experimental measurements, and the MICP data were acquired. Figure 7 displayed the MICP curves of these 6 core samples, the pore throat radius distribution and the corresponding NMT $T_{2}$ distribution. These core samples are classified into 2 groups based on the difference of porosities. For every group of core samples, the porosities are similar. From Fig. 7 we can observe that for core samples with different FZI, the pore structures are discrepant. Even if they contain similar porosity, the pore type and structure are entirely different. For a core sample with good pore structure, the corresponding FZI is high, and vice versa. For two groups of core samples, even if their petrophysical properties are discrepant, the regularities are analogous. Hence, these core samples should be classified, and a permeability estimation model should be established. 


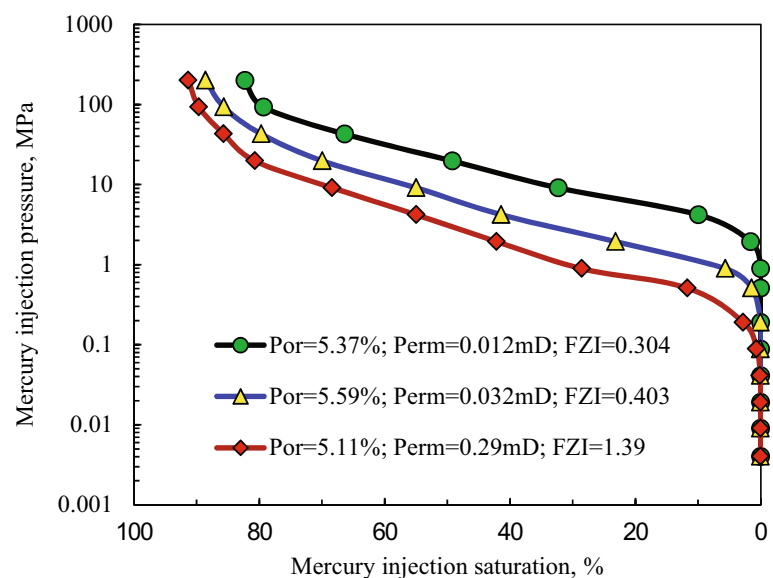

(a)

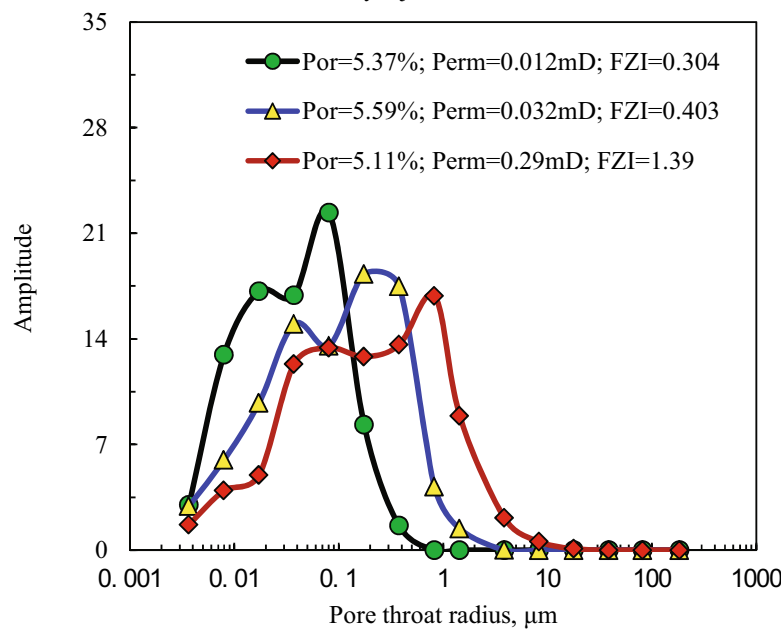

(b)

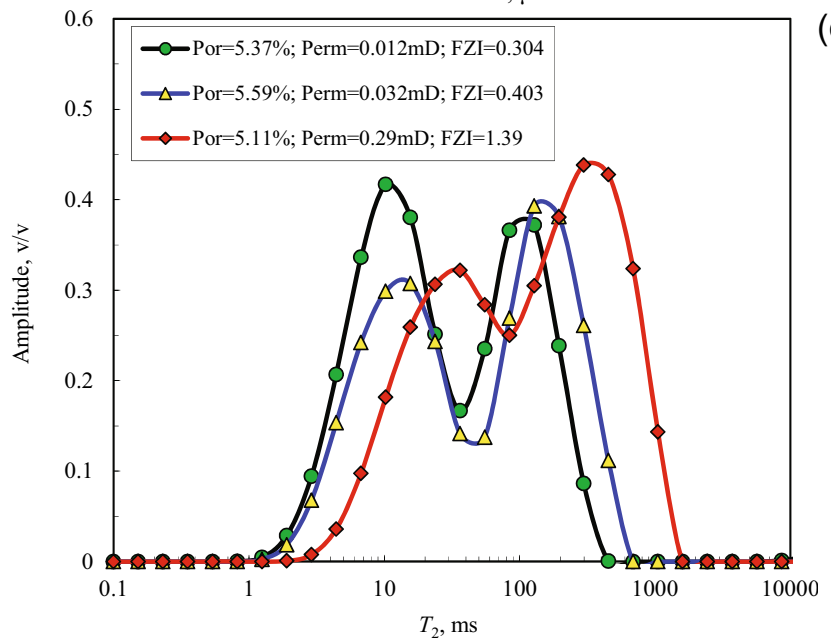

(c)

Fig. 7. Caption on next page. 


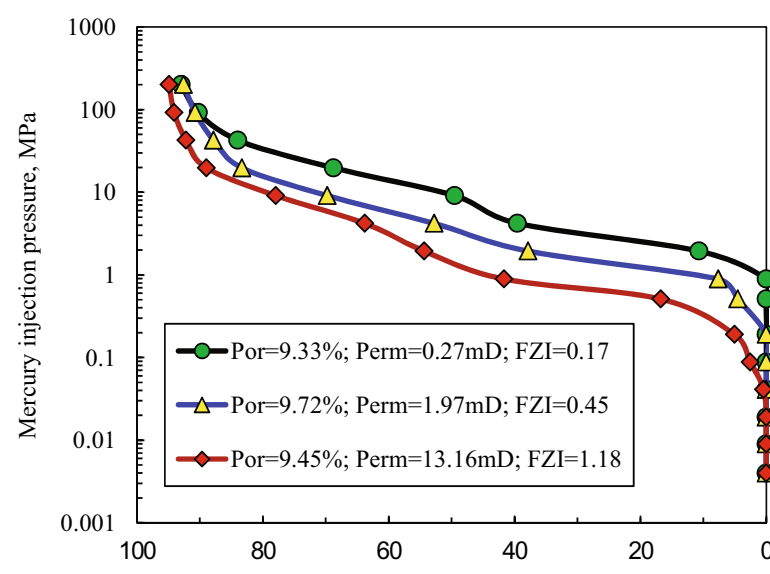

(d)

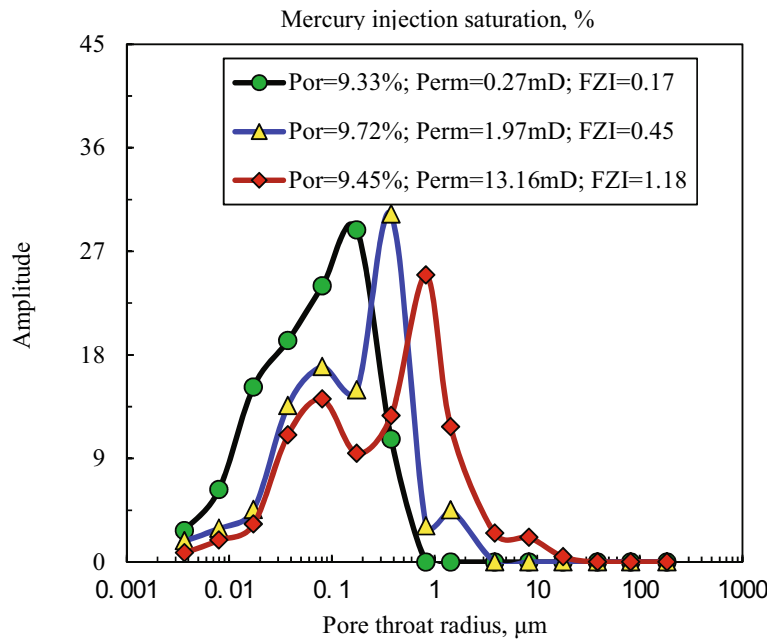

(e)

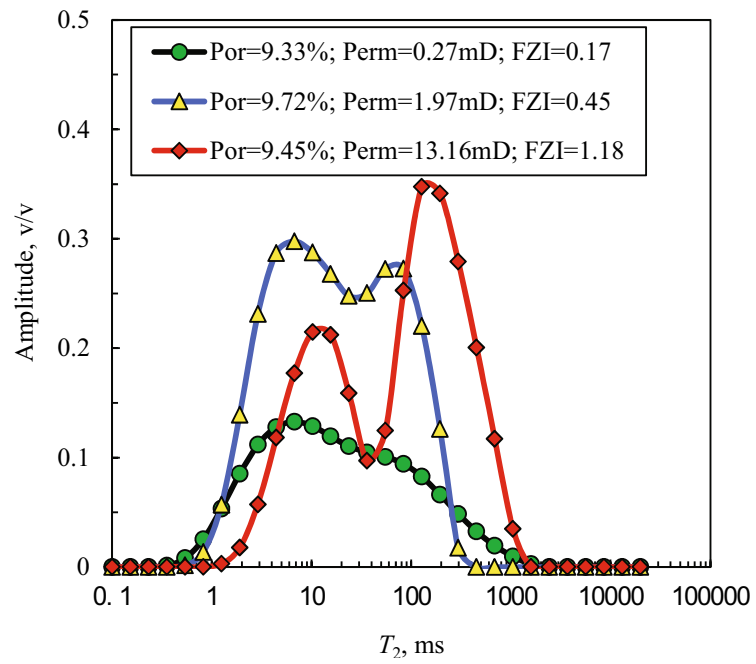

Fig. 7. Comparison of pore structure for 6 representative core samples with different FZI: (a) the MICP curves for 3 core samples with poor physical properties, (b) the pore throat radius distributions for 3 core sam(f) ples with poor physical properties, (c) the NMR $T_{2}$ spectra for 3 core samples with poor physical properties, (d) the MICP curves for 3 core samples with poor physical properties, (e) the pore throat radius distributions for 3 core samples with better physical properties, and (f) the NMR T2 spectra for 3 core samples with better physical properties. 


\subsection{Calibration of the SDR model}

With the same classification criteria of FZI, core samples displayed in Fig. 4 are classified into three types; the laboratory NMR measurements are reused to calibrate the involved parameters in the SDR model by using the multiple regression method. The rock classification criteria of FZI and the corresponding calibrated SDR models are listed in Table 1.

Table 1

Rock classification criteria of FZI and the corresponding calibrated SDR permeability estimation models in tight sandstone reservoirs of $\mathrm{E}$ basin in northwest China

\begin{tabular}{|l|l|l|c|}
\hline $\begin{array}{c}\text { Type } \\
\text { of rock }\end{array}$ & \multicolumn{1}{|c|}{$\begin{array}{c}\text { The classification } \\
\text { criteria of FZI }\end{array}$} & \multicolumn{1}{|c|}{ Calibrated SDR model } & $\begin{array}{c}\text { Correlation } \\
\text { coefficient } \\
\left(R^{2}\right)\end{array}$ \\
\hline 1st type & less than 0.32 & $K=0.0000019 \times \varphi^{4.24} \times T_{21 \mathrm{~m}}^{0.17}$ & 0.88 \\
2nd type & between 0.32 and 0.6 & $K=0.000057 \times \varphi^{2.90} \times T_{21 \mathrm{~m}}^{0.49}$ & 0.97 \\
3rd type & greater than 0.6 & $K=0.0036 \times \varphi^{4.08} \times T_{21 \mathrm{~m}}^{0.93}$ & 0.96 \\
\hline
\end{tabular}

From Table 1 it can be observed that the correlations of permeability with porosity and $T_{21 \mathrm{~m}}$ are improved for every type of rocks. The correlation coefficients are high enough, ensuring the applicability of SDR model in tight sandstone permeability prediction.

\subsection{Establishment of relationships for routine core derived porosity and permeability}

To verify the applicability of the theory of HFU in routine core analysis, it is also applied in core samples displayed in Fig. 1. By using the same classification criteria of FZI listed in Table 1, the core samples are reused, and they are also classified into three types. For every type of core samples, we attempt to establish the relationship of core derived porosity and permeability. The correlations of core derived porosity versus permeability are displayed

Table 2

Rock classification criteria of FZI and the corresponding relationships of core derived porosity and permeability those displayed in Fig. 1

\begin{tabular}{|c|l|l|c|}
\hline $\begin{array}{c}\text { Type } \\
\text { of rock }\end{array}$ & \multicolumn{1}{|c|}{$\begin{array}{c}\text { The classification } \\
\text { criteria of FZI }\end{array}$} & Calibrated SDR model & $\begin{array}{c}\text { Correlation } \\
\text { coefficient } \\
\left(R^{2}\right)\end{array}$ \\
\hline 1st type & less than 0.32 & $K=0.0017 \times \varphi^{2.70}$ & 0.87 \\
2nd type & between 0.32 and 0.6 & $K=0.0002 \times \varphi^{3.02}$ & 0.88 \\
3rd type & greater than 0.6 & $K=0.00007 \times \varphi^{3.00}$ & 0.82 \\
\hline
\end{tabular}




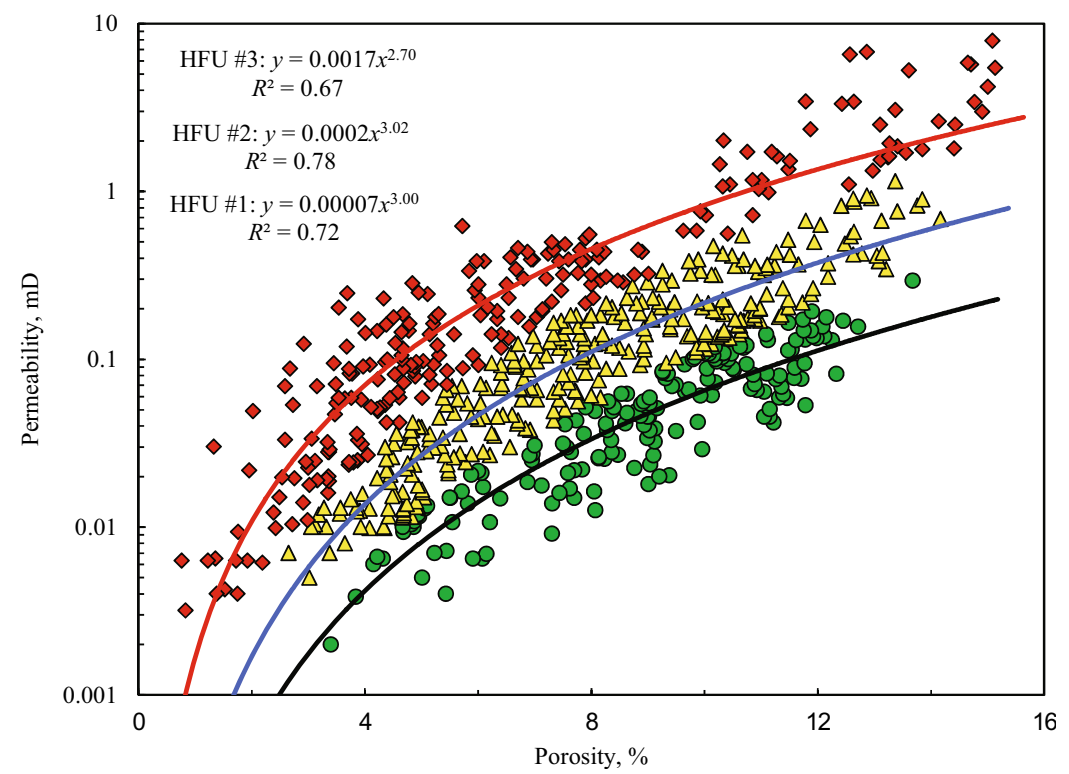

Fig. 8. Cross plots of porosity versus permeability for core samples with three different types of HFU.

in Fig. 8, and the corresponding permeability estimation models based on routine core analysis are listed in Table 2 . By using the list models, formation permeability can also be estimated from porosity. Analyzing Fig. 8 we can observe that for the first two types of core samples, the regressed trend lines can be used to express the relationship of porosity and permeability, whereas for the third type of core samples, the regressed model will underestimate the permeability in formations with permeability higher than $2.0 \mathrm{mD}$.

\subsection{Calculation of FZI from conventional logs}

\subsubsection{Establishment of FZI prediction model}

The above section has illustrated that the SDR model is applicable in tight sandstone permeability estimation once the FZI is introduced to classify rocks. To extend this proposed technique into field applications, consecutive FZI should be first calculated to classify formations. Abbaszadeh et al. (1996), D'Windt (2007), and Haghighi et al. (2011) pointed out that FZI can be calculated from conventional logs by using the multiple regression method. In this study, the multiple regression method is also applied to calculate FZI. The correlation analysis of obtained FZI from core porosity and permeability by using Eq. 12 and conventional logs illustrates that FZI is 
much sensitive to the interval transit time (AC), density (DEN), compensated neutron (CNL), natural gamma (GR), the ratio of deep and shallow lateral resistivity (LLD/LLS), and shale content (VSH) in our target tight gas sands. Hence, these six parameters are chosen to establish the FZI prediction model. In the process of establishing FZI calculation models, only 55 core samples were used, and the other 32 core samples were retained to verify the reliability of the estimated FZI. By using these 55 core samples, the FZI calculation model is calibrated and expressed as follows:

$$
\begin{aligned}
\mathrm{FZI} & =-0.0033 \times \mathrm{AC}-0.027 \times \mathrm{CNL}-0.0094 \times \mathrm{DEN}+0.0074 \times \mathrm{GR} \\
& +9.18 \times(\mathrm{LLD} / \mathrm{LLS})-0.13 \times \mathrm{VSH}-10.20 \text { correlation coefficient }=0.89 .
\end{aligned}
$$

From Eq. 14, it can be observed that good relationship exists between FZI and conventional logs. If it is applied in field applications, consecutive FZI can be calculated from conventional logs.

It is important to note that the parameter of LLD/LLS, which represents the drilling mud invasion characteristics, and thus fluid saturation, has been involved in Eq. 14. Hence, the FZI estimated from Eq. 14 should be heavily affected by the degree of drilling mud invasion and saturation conditions, and the applicability of Eq. 14 should been reduced in formations with significant drilling mud invasion.

Fortunately, in our target tight gas sands, the drilling mud invasion is not obvious due to the poor permeability, the amplitude difference of deep and shallow lateral resistivity is not prominent, and the contribution of LLD/LLS to FZI is not primary. Therefore, Eq. 14 can be well used to estimate FZI in tight gas sands of $\mathrm{E}$ basin.

\subsubsection{Reliability verification for FZI estimation}

To verify the reliability of these FZI estimation models, expressed in Eq. 14, in field applications, it is applied to tight sandstone reservoirs in the E basin to obtain FZIs from conventional logs, and they are compared with laboratory derived results for 32 core samples. Figure 9 shows the cross plot of derived FZI from 32 core samples and predicted results by using Eq. 14. The solid lines in this figure represent the diagonal lines, which clarify the discrepancy of the calculated FZI with that of the core analyzed results. This figure demonstrates that the FZIs estimated by using Eq. 14 and the core derived results locate in the neighborhood of the diagonal lines. This means that the predicted FZIs by using Eq. 14 are acceptable, and Eq. 14 can be applied in field applications to calculate consecutive FZI, and then the permeability estimation formulae listed in Table 1 can be used for accurate permeability prediction. 


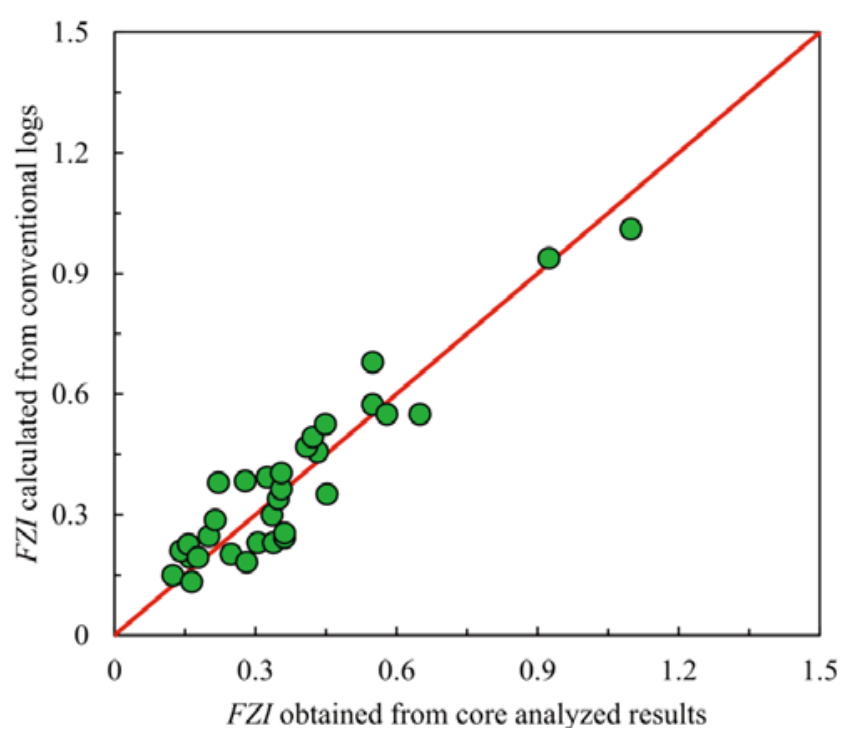

Fig. 9. Comparison of FZI acquired from core samples and calculated from conventional logs.

\section{CASE STUDY}

Based on the proposed technique, several wells in the $\mathrm{E}$ basin of northwest China are processed, and the corresponding tight gas sandstone permeability is estimated. In the process of field applications, we should note that all permeability estimation formulae based on the SDR model are established with laboratory NMR measurements from fully brine saturated core samples. If it is used in field tight gas reservoirs, the effect of diffusion relaxation of natural gas to NMR logs (NMR porosity and $T_{21 \mathrm{~m}}$ ) should be considered. In regard to the porosity calculation in tight gas sands, Xiao et al. (2012a, b, c) had proposed appropriate model, and it had been verified to be effective in tight gas porosity calculation in the E basin. Hence, it is directly citied in this study to acquire precise porosity. In regard to the gas correction of $T_{2 \mathrm{Im}}$, Xiao et al. $(2012 \mathrm{a}, \mathrm{b}, \mathrm{c})$ pointed out that a relationship of between $T_{2 \mathrm{~m}}$ acquired from field NMR logs and measured from core samples under fully brine saturated can be established, and it was widely applicative. Based on the method proposed by Xiao et al. (2012a, b, c), a relationship is also established to correct the effect of natural gas to NMR $T_{21 \mathrm{~m}}$, as is shown in Fig. 10. From Fig. 10 we can observe that good relationship exists between the $T_{21 \mathrm{~m}}$ acquired from field NMR logs and measured from core samples that were fully brine saturated. With this relationship, the effect of natural gas to field NMR $T_{21 \mathrm{~m}}$ can be diminished, and, using the corrected NMR parameters, little errors should be introduced in permeability estimation. 


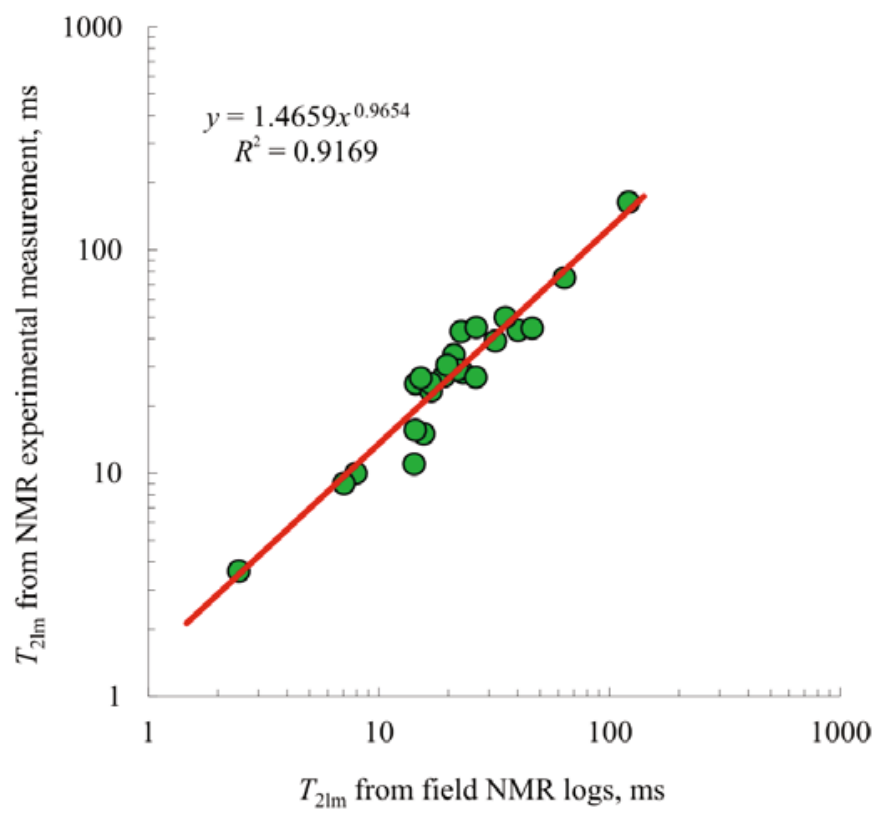

Fig. 10. A relationship between $T_{2 \operatorname{lm}}$ acquired from field NMR logs and from core measurement under full brine-saturation in the target tight gas sands of $\mathrm{E}$ basin.

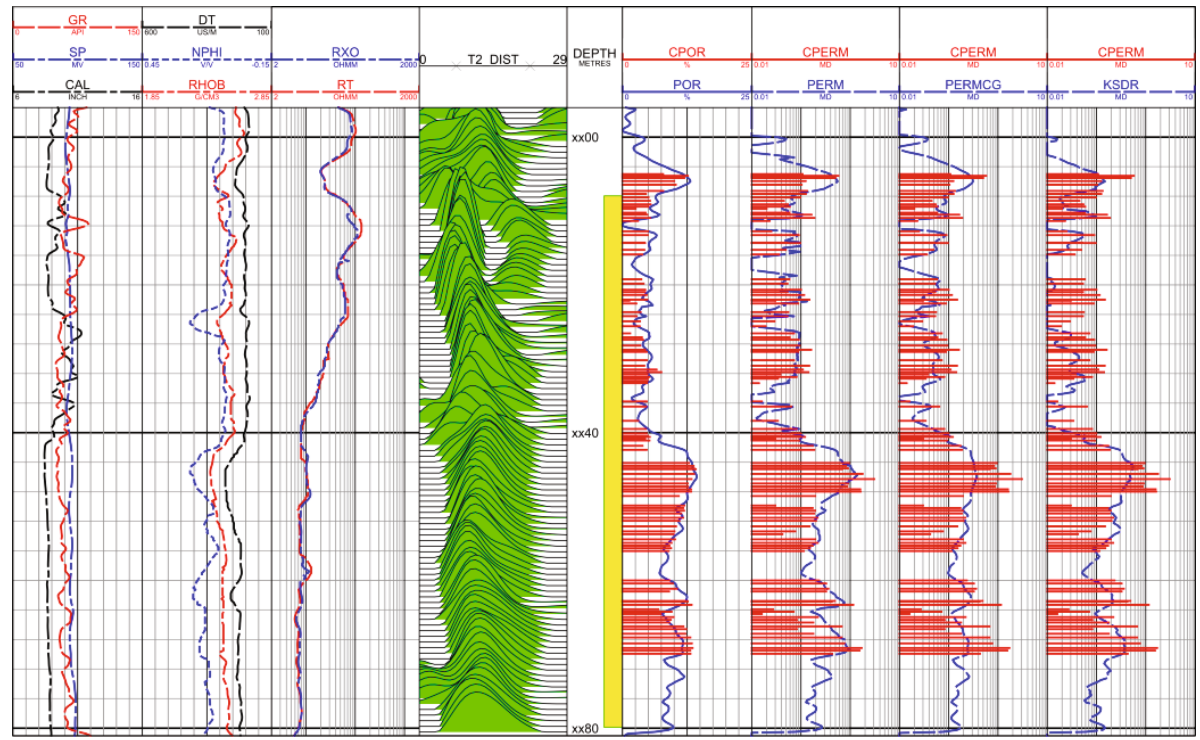

Fig. 11. Comparisons of permeabilities estimated from field NMR logs by using three methods. 
Figure 11 shows a field example of estimating permeability in the E basin. In the first track, the displayed curves are gamma ray (GR), spontaneous potential (SP), and borehole diameter (CAL), they are used for effective formation indication. In the second track, we display the curves of density $\log (\mathrm{DEN})$, compensated neutron $\log (\mathrm{CNL})$, and interval transit time $\log (\mathrm{AC})$.

They are used for porosity estimation. RT displayed in the third track is deep lateral resistivity, and RXO is shallow lateral resistivity. $T_{2}$ distribution displayed in the fourth track is field NMR $T_{2}$ spectrum, which was acquired from the Halliburton's MRIL-C tool, and $T_{21 \mathrm{~m}}$ is the logarithmic mean of the NMR $T_{2}$ distribution. The fifth track is depth and its unit is meter. In the sixth track of Fig. 11, we display the comparison of routine core derived porosity (CPOR) and NMR derived porosity (POR), and POR is calculated from field NMR and conventional acoustic log using method proposed by Xiao et al. (2012a, b,c). This comparison illustrates that the calculated porosity matches the core derived porosity very well, which means that POR is reliable and little error will be brought in when it is applied in permeability estimation. PERM displayed in the seventh track is the formation permeability estimated from field NMR logs by using the proposed technique, and CPERM is the core analyzed permeability. PERMCG displayed in the eighth track is permeability curve obtained by using the models listed in Table 2, and it is directly predicted from porosity after formations are classified into three types by the difference of FZI. KSDR displayed in the last track is permeability estimated from field NMR logs by using the unified SDR model without formation classification. From the comparisons displayed in these three tracks, we can observe that permeabilities can be precisely estimated from field NMR logs once tight gas sandstone reservoirs are classified into three types by using the difference of FZI and the corresponding calibrated SDR models are applied. Models established by using the routine core analyzed results are effective for formations with permeability lower than $0.3 \mathrm{mD}$, while in formations with permeability higher than $0.3 \mathrm{mD}$, PERMCG is underestimated. However, formation permeability can only be effectively predicted in the intervals with permeability ranges from 0.1 to $0.3 \mathrm{mD}$ by using the unified SDR model. When formation permeability is higher than $0.3 \mathrm{mD}$ or lower than $0.1 \mathrm{mD}$, permeability will be underestimated from the unified SDR model. The accuracy of estimated permeability was confirmed by drill stem testing data, in the interval of xx08 to xx80 m (highlighted in Fig. 11), $3.12 \times 10^{4} \mathrm{~m}^{3} /$ day of gas production is acquired and the dynamic permeability acquired from well testing in this interval is $0.65 \mathrm{mD}$. To make the estimated results from different methods can represent the true permeability of the whole test interval they are all normalized by using thickness weighted average method. The results illustrate that per- 
meabilities estimated from the calibrated SDR models based on FZI classification, the conventional method by using the models listed in Table 2 and the unified SDR model in the same interval are $0.57,0.42$, and $0.36 \mathrm{mD}$, separately, while the average core derived permeability in this interval is $0.6 \mathrm{mD}$. These comparisons adequately show that the technique proposed in this study is much more effective in tight gas sands permeability estimation. Permeability calculated by using calibrated SDR models based on FZI classification is very close to the core derived result and dynamic permeability, whereas permeabilities estimated by using the other two methods are all much underestimated.

\section{DISCUSSIONS}

To intuitively illustrate the improvement of permeability estimation by using the calibrated SDR models based on formation classification method, permeabilities acquired from four different kinds of methods are compared and they are displayed through Figs. 12 to 14, respectively. To carefully analyze the applicability of the models mentioned in this study, core samples with different FZI values are marked with different colour code. The blue lines in these three figures represent the diagonal lines which highlight the discrepancy of predicted permeability with those of core analyzed results.

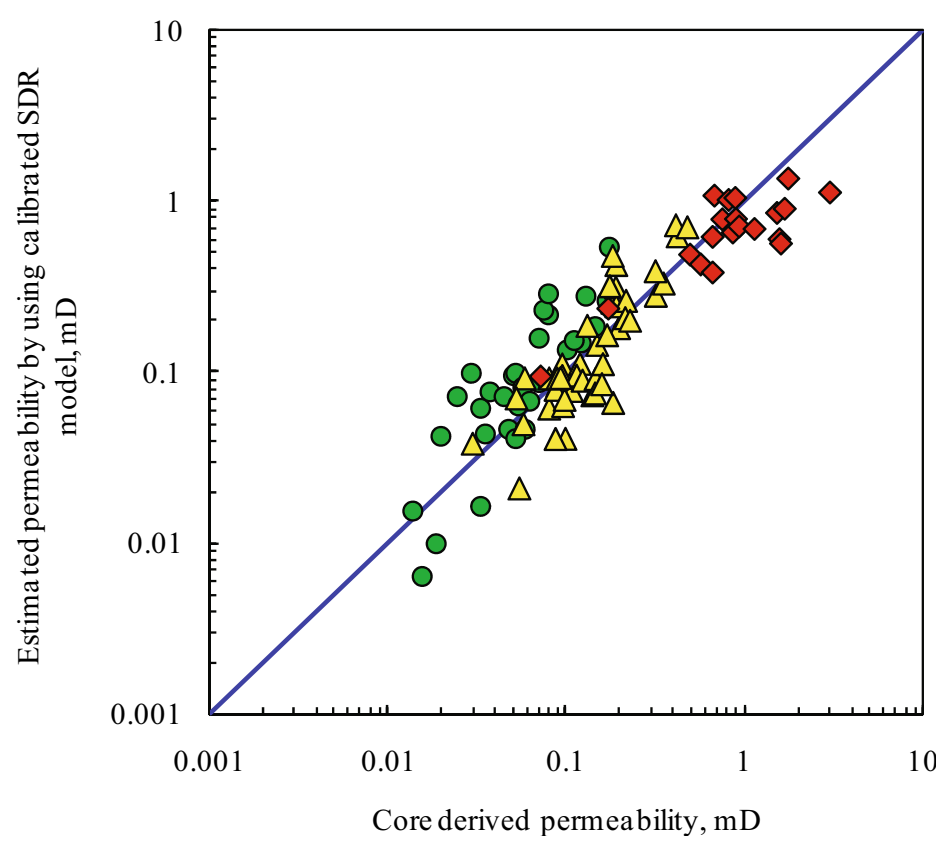

Fig. 12. Cross plot of core derived permeability versus estimated permeability by using calibrated SDR models. 


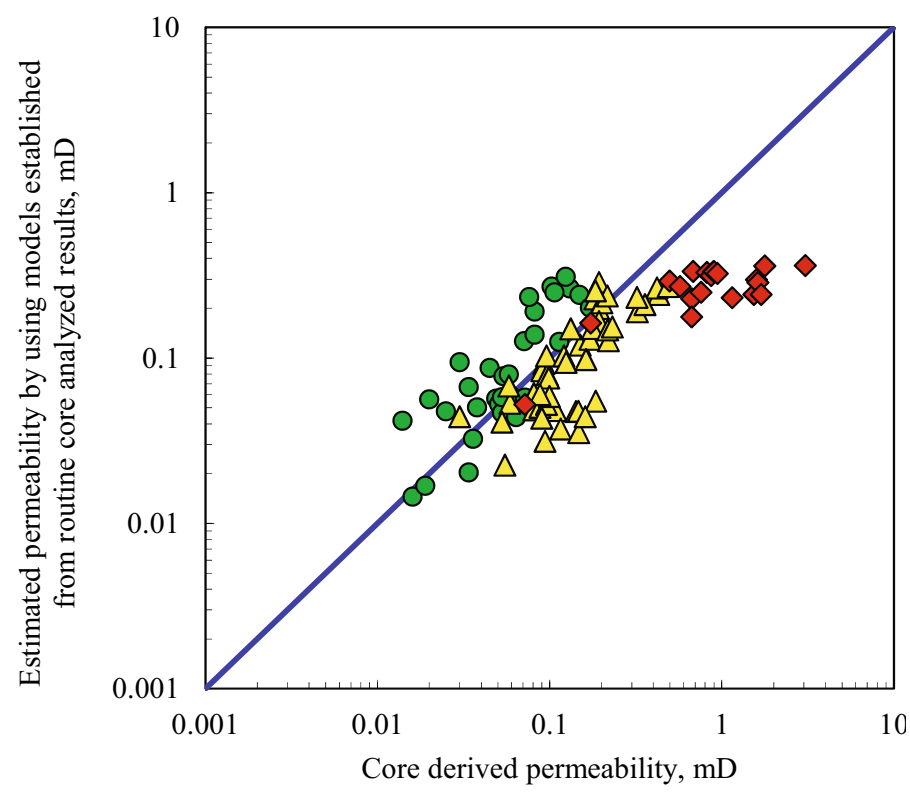

Fig. 13. Cross plot of core derived permeability versus estimated permeability by using established models from routine core analyzed results based on FZI classification.

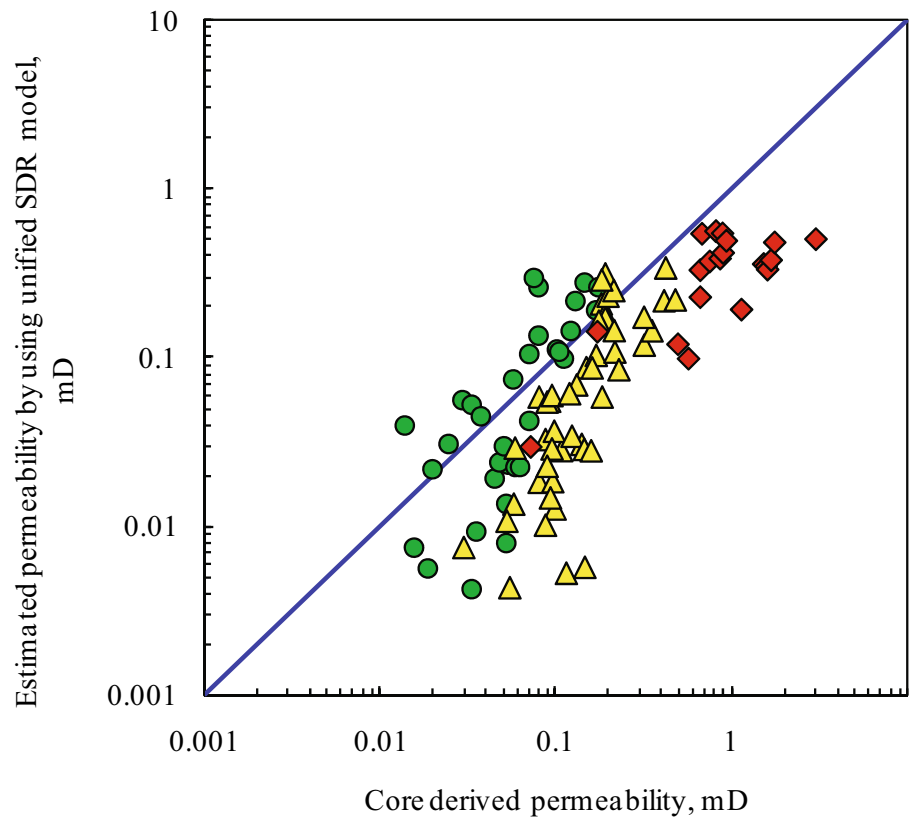

Fig. 14. Cross plot of core derived permeability versus estimated permeability by using unified SDR models. 
Figure 12 demonstrates that the permeabilities estimated by using the calibrated SDR models based on FZI classification, and the core derived results, are located in the vicinity of the diagonal line for almost all core samples, which indicates that permeabilities obtained from these two methods are approximate. From Fig. 13, however, we can observe that the permeabilities predicted by using the established models from routine core analyzed results based on FZI classification only match the core derived results when permeabilities are lower than $0.3 \mathrm{mD}$. In this range, the data points are located in the vicinity of the diagonal line, while they are much more divergent than those of the calibrated SDR models. For formations with different type of FZI, the accuracy of permeability estimation is not disparate. For formations with the third type of FZI and permeabilities that are higher than $0.3 \mathrm{mD}$, these models underestimate the formation permeability. This coincides with the results displayed in Fig. 8 .

Figure 14 indicates that the unified SDR model is effective in permeability estimation when formation permeabilities range from 0.1 to $0.3 \mathrm{mD}$, and the corresponding formations contain the first type of FZI. In the other cases, permeabilities are underestimated. This observation is consistent with those displayed in Fig. 11.

From these comparisons, displayed in Figs. 11 to 14, we can observe that the accuracy of tight gas sandstone permeability estimation is not high enough from NMR logs by using the unified SDR model; once the formations are classified into three types based on the difference of FZI, and the above-mentioned parameters in the SDR model are calibrated separately, the permeability prediction is much improved. Although permeability can be estimated from porosity after formations are classified into three types based on the difference of FZI, and the estimated permeabilities are much more precise than those obtained from unified SDR models, the accuracy needs to be improved for tight gas sands evaluation; the reasons may be that the input parameter used is the logarithmic mean of NMR $T_{2}$ spectra except of the porosity in the calibrated SDR models, and the logarithmic mean of NMR $T_{2}$ spectra is the response of pore structure. However, the models established from routine core analyzed results only contain univocal porosity, and from Fig. 8 we can also observe that the relevance between core derived porosity and permeability is not high enough, and, especially for the third type of rocks, permeability should be underestimated by using the regressed relationship. Maybe, the permeability can be much more precisely estimated from porosity after formations are classified into many more types, but the processing procedure should be complicated, and many more median errors may be introduced. 


\section{CONCLUSIONS}

a The classical Timur-Coates model is poorly applicable in permeability estimation, because it is difficult to accurately obtain the involved parameters of FFI and BVI from NMR logs at present.

口 If the SDR model is directly applied in tight gas sandstone permeability prediction with the unified calibrated parameters, precise permeability can only be estimated in the intervals with permeability ranges from 0.1 to $0.3 \mathrm{mD}$; when formation permeability is higher than $0.3 \mathrm{mD}$ or lower than $0.1 \mathrm{mD}$, the formation permeability will be underestimated.

- After core samples are classified into three types based on the differences of FZI, the above-mentioned parameters in the SDR model can be calibrated, respectively. Once the same criteria are applied to field applications, formations can be classified and the corresponding SDR models can be used to effectively improve the permeability estimation in tight sandstone reservoirs.

\section{References}

Abbaszadeh, M., H. Fujii, and F. Fujimoto (1996), Permeability prediction by hydraulic flow units - theory and applications, SPE Formation Eval. 11, 4, 263-271, DOI: 10.2118/30158-PA.

Coates, G.R., L.Z. Xiao, and M.G. Prammer (1999), NMR Logging - Principles and Applications, Gulf Publ. Co., Houston, 256 pp.

D'Windt, A. (2007), Reservoir zonation and permeability estimation: A Bayesian approach. In: Proc. 48th SPWLA Annual Logging Symposium, 3-6 June 2007, Austin, USA, paper UUU.

Delli, M.L., and J.L.H. Grozic (2013), Prediction performance of permeability models in gas-hydrate-bearing sands, SPE J. 18, 2, 274-284, DOI: 10.2118/ 149508-PA.

Deng, J.M., X.X. Hu, X.P. Liu, and X.M. Wu (2013), Estimation of porosity and permeability from conventional logs in tight sandstone reservoirs of north Ordos basin. In: SPE Unconventional Gas Conference and Exhibition, 2830 January 2013, Muscat, Oman, SPE163953, DOI: 10.2118/163953-MS.

Dunn, K.-J., D.J. Bergman, and G.A. Latorraca (2002), Nuclear Magnetic Resonance: Petrophysical And Logging Applications, Handbook of Geophysical Exploration, Vol. 32, Pergamon, New York, 176 pp.

Gao, J.B., L.T. Sun, and C.R. Wang (1991), Development of a transient pulse permeameter for tight rocks, Chin. J. Sci. Instr. 12, 4, 365-371 (in Chinese).

Haghighi, M.B.P., M. Shabaninejad, and K. Afsari (2011), A permeability predictive model based on hydraulic flow unit for one of Iranian carbonate tight gas 
reservoir. In: SPE Middle East Unconventional Gas Conference and Exhibition, 31 January - 2 February 2011, Muscat, Oman, SPE 142183, DOI: 10.2118/142183-MS.

Hearn, C.L., W.J. Ebanks Jr., R.S. Tye, and V. Ranganathan (1984), Geological factors influencing reservoir performance of the Hartzog Draw field, Wyoming, J. Petrol. Technol. 36, 8, 1335-1347, DOI: 10.2118/12016-PA.

Hulea, I.N. (2013), Capillary pressure and permeability prediction in carbonate rocks - New methods for fractures detection and accurate matrix properties prediction. In: SPE Middle East Oil and Gas Show and Conference, 10-13 March 2013, Manama, Bahrain, SPE164251, DOI: 10.2118/164251-MS.

Hulea, I.N., and C.A. Nicholls (2012), Carbonate rock characterization and modeling: Capillary pressure and permeability in multimodal rocks - A look beyond sample specific heterogeneity, AAPG Bull. 96, 9, 1627-1642, DOI: 10.1306/02071211124.

Kenyon, W.E. (1997), Petrophysical principles of applications of NMR logging, The Log Analyst 38, 2, 21-43.

Kenyon, W.E., P.I. Day, C. Straley, and J.F. Willemsen (1988), A three-part study of NMR longitudinal relaxation properties of water-saturated sandstones, SPE Formation Eval. 3, 3, 622-636, DOI: 10.2118/15643-PA.

Lucia, F.J. (1995), Rock-fabric/petrophysical classification of carbonate pore space for reservoir characterization, AAPG Bull. 79, 9, 1275-1300.

Mao, Z.Q., Z.N. Wang, Y. Jin, W.N. Zhou, X.G. Liu, and B. Xie (2008), Study on petrophysical foundation, methodology and techniques of logging reservoir evaluation for Upper Triassic Xujiahe Formation in Sichuan Basin, Well Log. Technol. 31, 3, 203-206.

Mao, Z.Q., L. Xiao, Z.N. Wang, Y. Jin, X.G. Liu, and B. Xie (2013), Estimation of permeability by integrating nuclear magnetic resonance (NMR) logs with mercury injection capillary pressure (MICP) data in tight gas sands, Appl. Magn. Reson. 44, 4, 449-468, DOI: 10.1007/s00723-012-0384-z.

Morriss, C., D. Rossini, C. Straley, P. Tutunjian, and H. Vinegar (1997), Core analysis by low-field NMR, The Log Analyst 38, 2, 84-94.

Rezaee, R., A. Saeedi, and B. Clennell (2012), Tight gas sands permeability estimation from mercury injection capillary pressure and nuclear magnetic resonance data, J. Petrol. Sci. Eng. 88-89, 92-99, DOI: 10.1016/j.petrol.2011. 12.014 .

Salah, A. (2012), The impact of pore geometry aspects on porosity-permeability relationship - a critical review to evaluate NMR estimated permeability. In: North Africa Technical Conference and Exhibition 2012, 20-22 February 2012, Cairo, Egypt, 808-818, SPE150887, DOI: 10.2118/150887-MS.

Tiab, D., D.M. Marschall, and M.H. Altunbay (1993), Method for identifying and characterizing hydraulic units of saturated porous media: tri-kappa zoning process, U.S. Patent No. 5193059 A. 
Xiao, L., Z.Q. Mao, and Y. Jin (2012a), Calculation of irreducible water saturation $\left(\mathrm{S}_{\text {wirr }}\right)$ from NMR logs in tight gas sands, Appl. Magn. Reson. 42, 1, 113125, DOI: 10.1007/s00723-011-0273-X.

Xiao, L., Z.Q. Mao, G.R. Li, and Y. Jin (2012b), Calculation of porosity from nuclear magnetic resonance and conventional logs in gas-bearing reservoirs, Acta Geophys. 60, 4, 1030-1042, DOI: 10.2478/s11600-012-0015-y.

Xiao, L., Z.Q. Mao, Z.N. Wang, and Y. Jin (2012c), Application of NMR logs in tight gas reservoirs for formation evaluation: A case study of Sichuan basin in China, J. Petrol. Sci. Eng. 81, 182-195, DOI: 10.1016/j.petrol.2011.12. 025 .

Xiao, L., X.P. Liu, C.C. Zou, X.X. Hu, Z.Q. Mao, Y.J. Shi, H.P. Guo, and G.R. Li (2014), Comparative study of models for predicting permeability from nuclear magnetic resonance (NMR) logs in two Chinese tight sandstone reservoirs, Acta Geophys. 62, 1, 116-141, DOI: 10.2478/s11600-013-0165-6.

Xiao, Z.X., and L. Xiao (2008), Method to calculate reservoir permeability using nuclear magnetic resonance logging and capillary pressure data, Atom. Ener. Sci. Technol. 42, 10, 868-971 (in Chinese).

Yang, M.S. (2001), Study of optimal work condition about instantaneous-pulse permeability test equipment, J. Southwest Petrol. Inst. 23, 1, 46-48 (in Chinese).

Received 20 January 2014 Received in revised form 8 July 2014

Accepted 14 July 2014 